\title{
Talented enough to be a business leader? An alternative approach to entrepreneurs' traits
}

\author{
Przemysław Zbierowski, Milena Gojny-Zbierowska
}

\begin{abstract}
A B S T R A C T
Objective: The objective of the article is to identify character strengths that contribute to one's success at various stages of the development of an entrepreneurial venture: opportunity recognition, the refinement of business concept, resource acquisition, survival, and growth.
\end{abstract}

Research Design \& Methods: The article is conceptual in nature. We propose a framework of character strengths and stages of development of the entrepreneurial venture, which is based on an exhaustive literature review.

Findings: The article proposes that different character strengths contribute to one's success at various stages of venture development: curiosity, creativity, open-mindedness, and hope at the stage of opportunity recognition; bravery, integrity, love of learning, social intelligence, and kindness at the stage of refinement of business concept and resource acquisition; persistence, self-regulation, zest, humour, leadership, teamwork, and fairness at the stage of survival and growth. Moreover, We propose that perspective allows entrepreneurs to accumulate experience and recognize and exploit further opportunities.

Implications \& Recommendations: The study has implications mainly for entrepreneurs (recommendation for higher self-awareness) and investors (investment in entrepreneur's strength bundled with investment in the business).

Contribution \& Value Added: This study adds to the understanding of mechanisms through which personal differences influence entrepreneurial actions and their outcomes. It adds to our understanding of specific entrepreneurship phenomena like entrepreneurial alertness or business planning. Thirdly, it contributes to the understanding not only of market entry but also of pre-entry and post-entry phenomena.

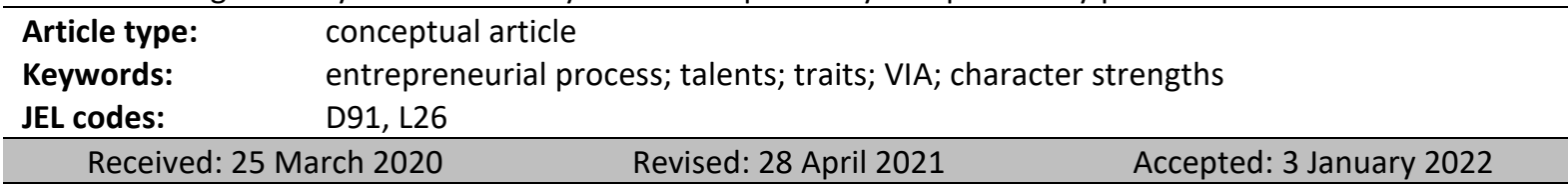

\section{Suggested citation:}

Zbierowski, P., \& Gojny-Zbierowska, M. (2022). Talented enough to be a business leader? An alternative approach to entrepreneurs' traits. Entrepreneurial Business and Economics Review, 10(1), 175-187. https://doi.org/10.15678/EBER.2022.100112

\section{INTRODUCTION}

Entrepreneurship is undoubtedly important for economy and society (Meyer \& Krüger, 2021). If we agree with Shane and Venkataraman (2000) that entrepreneurship is the identification and exploitation of business opportunities within the individual-opportunity nexus, then how important is the 'individual' in that dyad? This question was posed decades ago but was later abandoned due to the false assumption that personality research could not offer anything useful (Gartner, 1988; Aldrich, 1999). However, during the last decade we have experienced a renaissance of research on entrepreneurs' personality (Frese \& Gielnik, 2014; Castellanos \& George, 2020; Tshikovhi, Dziike, \& Moyo, 2021; Wardana, Narmaditya, Wibowo, Fitriana, Saraswati, \& Indriani, 2021). The rekindled scholarly interest in the matter was caused by the more fine-tuned approach to traits, which separated high and low matches by taking into consideration proximal and distal traits - and by more sophisticated methods of investigation. The research effort 
resulted in the discovery of a set of personality drivers of business activity. Nevertheless, Frese and Gielnik (2014) indicate two missing links. First is the possible mediator between personality traits (distal and proximal) and entrepreneurship outcomes. Second is the difference in importance of various traits at stages of entrepreneurial activity: opportunity identification, the refinement of business concept and resource acquisition, survival and growth. We address these suggestions by indicating positive psychology-based construct of character and signature strengths as drivers of entrepreneurial behaviour. Therefore, the main question of this article is: Which character strengths contribute to entrepreneurship at various stages of venture development? The main purpose of this article is to identify those strengths based on literature review and scarce empirical evidence.

This study contributes to the literature in entrepreneurship in a couple of ways. First, it adds to the understanding of mechanisms through which personal differences influence entrepreneurial actions and their outcomes, as suggested by Mischel and Shoda (1998). We do it by considering a number of talents and their possible contribution to business activities. Second, as suggested by Frese and Gielnik (2014), this study adds to the understanding of specific entrepreneurship phenomena like entrepreneurial alertness or business planning. Third, it contributes to our understanding of not only market entry but also some pre-entry and post-entry phenomena (Levie \& Autio, 2011). Finally, the article contributes to the broader literature on the use of signature strengths by analyzing the potential effect of certain character strengths on the entrepreneurial process.

The article is conceptual in nature, and it is structured in the following way. After presenting the method of the investigation, we present the theoretical foundations of using the category of strength in psychology and management research. Taking the person-entrepreneurship perspective, we begin by referring to research on personality of entrepreneurs. Then, we turn to even more proximal traits of entrepreneurs: their talents and strengths. We present the framework of virtues and character strengths so as to turn to considerations of their role in entrepreneurship, and education plays a very crucial role in this process (Solesvik, 2019; Rodríguez-Castro \& Aparicio, 2021). The essential part of the article lies in the conceptual framework of the contribution of strengths at various stages of venture development. The article concludes with practical implications, study limitations, and future research directions.

\section{RESEARCH METHODOLOGY}

This article is conceptual in nature. Due to the very limited number of studies in this area, the applied method was exhaustive literature review. We used a variety of search methods (Web of Science, Ebsco, Google Scholar) to identify the scholarly publications related to the possession and use of strengths by entrepreneurs. We used search words 'strength,' 'character strength,' 'entrepreneur,' 'business owner,' and related terms. Then, we filtered and excluded the publications that related to 'strength of the character' rather th an to 'character strength.' This search yielded only a very limited number of articles. Therefore, no selection criteria were applied. Below, we scrutinise all scholarly publications that refer to entrepreneurs' strengths.

\section{LITERATURE REVIEW AND THEORY DEVELOPMENT}

\section{Character strengths as proximal personality traits}

Most studies that consider the role of personality traits in entrepreneurial behaviour and success/growth concentrate on general personality traits (Wach \& Głodowska, 2021), mostly dimensions of personality frameworks such as 'Big Five' ('distal variables'); some take into consideration specific traits such as selfefficacy, achievement motivation, proactiveness, risk propensity (often considered together with 'Big Five' as 'Big Five+'), innovativeness, stress tolerance, and autonomy or locus of control ('proximal variables') as explained by Rauch and Frese (2007); creativity as a personality trait is rarely studied in entrepreneurship research. Specific traits might lead to more specific processes, while proximal individual differences are closer to behaviour and more powerful predictors of behaviour than distal individual differences (Rauch \& Frese, 2000; 2007). Moreover, Rauch and Frese (2007) propose a framework in which 
proximal variables (specific traits) result from distal variables (the Big Five dimensions). Their study further unpacks the mechanism through which personality affects entrepreneurial activity. Therefore, character strengths replace "goals, growth goals, visions and action strategies" presented in the model by Rauch and Frese (2007) as mediators between proximal (specific) personality traits, along with business creation and success. Rauch and Frese (2007) suggest that variables that are even more proximal to behaviour (such as processes related to personality: cognitive, or self-regulatory processes) than specific personality traits might lead to even stronger relationships. The application of character strengths framework to 'personality of entrepreneurship' research might bring the benefit of a more fine-grained understanding of the effect of personality on entrepreneurial actions and their results. In this vein, signature strengths would be even closer to behaviour than 'proximal variables.'

We consider character strengths as talents and place 'strengths of the character' in the vicinity of possible approaches to talents (natural preconditions, mastering the capability, engagement and motivation, strengths of character; Heslin et al., 2005; Pfeffer \& Sutton, 2006; Nijs et al., 2014). However, there are a few approaches to strengths of character. Miglianico et al. (2020) compare three leading frameworks of strengths: Buckingham's and Clifton's (2001) StrengthsFinder with 34 strengths, Peterson's and Seligman's (2004) character strengths with 24 strengths grouped within 6 virtues, and Linley's (2008) Strengths Profile with 60 strengths. The most widespread Peterson and Seligman's (2004) framework offers a number of measures ranging from 72 to 240 items with Cronbach's alpha estimates ranging from 0.62 to 0.90 ( 0.75 to 0.90 for the 240 -item scale). Furthermore, Peterson (2006) maps character strengths in a two-dimensional space according to their origin in either heart or mind, along with a focus on self or others. The farther apart the two strengths are, the less likely the same person habitually shows both of them.

Allow us to highlight three features of character strengths. First, there is a consensus that strengths are naturally present within individuals. Some authors suggest that signature strengths are anchored in neural networks, which would explain the ease with which they are used by a person and the sense of authenticity and energy resulting from their use (Buckingham \& Clifton, 2001; Linley, 2008). Second, while strengths are relatively stable, they fluctuate and can be developed continuously over the course of a lifetime (Biswas-Diener, 2006; Park et al., 2006). However, some authors claim that strengths fulfil the criterion of personality trait raised by Rauch and Frese (2007), Buckingham and Clifton, (2001) and Linley (2008). We may at least posit that strengths are grounded in personality, and individuals with different personalities use different strengths (Bakker et al., 2019). Third, levels of character strengths vary across countries as cultural institutions that encourage strengths and virtues are identified in many different cultures (Biswas-Diener, 2006).

The framework of character strengths is grounded in positive psychology, which is the scientific study of what is best in people and of characteristics and conditions of life that contribute to good life (Seligman \& Csikszentmihalyi, 2000). Peterson and Seligman (2004) propose a framework of twentyfour character strengths (e.g. appreciation of beauty and excellence, perseverance, love, hope, zest) grouped within six virtues (wisdom and knowledge, courage, humanity, justice, temperance, and transcendence) based on works in various areas (religion, philosophy, psychology, culture). Character strengths are then defined as positively valued trait-like individual differences with demonstrable generality across different situations and stability across time (Peterson \& Seligman, 2004). Strengths are ways of displaying virtues, e.g. courage can be achieved by the display of perseverance (goal orientation, overcoming of obstacles, finishing what is started), bravery (facing fears, overcoming challenges and adversity, standing up for what is right, not shrinking in the face of pain or inner tension or turmoil), honesty (high integrity and authenticity, telling truth even when it hurts, presenting to others in a sincere way, taking responsibility for actions), and zest (enthusiasm toward life, high energy and activation, using one's energy to the fullest degree). The framework is known under the name of Values in Action (VIA) classification. Character strengths that are the personally highest strengths are defined as "signature strengths." Seligman states that using signature strengths "leads to more positive emotions, more meaning, more accomplishment, and better relationships" (2011, p. 24). A full framework of virtues and character strengths is presented in Table 1 below. 
Table 1. Virtues and character strengths: a theoretical model

\begin{tabular}{|c|c|c|c|c|c|}
\hline Transcendence & Temperance & Justice & Humanity & Courage & Wisdom \\
\hline $\begin{array}{l}\text { Appreciation of } \\
\text { beauty \& excellence }\end{array}$ & Forgiveness \& mercy & Teamwork & Love & Bravery & Creativity \\
\hline Spirituality & Humility \& modesty & Fairness & Kindness & Persistence & Curiosity \\
\hline Gratitude & Prudence & Leadership & Social intelligence & Integrity & Open-mindedness \\
\hline Hope & Self-regulation & - & - & Zest & Love of learning \\
\hline Humour & - & - & - & - & Perspective \\
\hline
\end{tabular}

Source: own elaboration based on Peterson and Seligman (2004).

Results of the literature review on strengths use at the workplace indicate that strengths use is associated with job satisfaction, work engagement, well-being, and work performance (Miglianico et al., 2020). However, most literature to date focuses on strengths development interventions rather than on strengths possession and use as such. Earlier reviews (Quinlan et al., 2012; Ghielen et al., 2017; Coppola et al., 2018) focus on strengths development interventions studies conducted mainly with experimental and quasi-experimental designs. They find that such interventions positively influence various measures of well-being (e.g. positive affect, life satisfaction, depression), vitality, flow, passion and engagement at work, job outcomes (e.g. work performance, work engagement, lower level of absenteeism), personal growth initiative and group outcomes (e.g., information sharing, class cohesion). The effect of strengths use on work performance and well-being is explained by various theories including the broaden-and-build theory (Fredrickson, 2001) and the self-determination theory (Ryan \& Deci, 2000). Forest et al. (2012) prove that the explanation (and mediator) of the effect of strengths use on well-being is harmonious passion.

Moreover, strengths use is associated to the sense of meaning at work (Harzer \& Ruch, 2013; Littman-Ovadia et al., 2017; Littman-Ovadia \& Steger, 2010; Nagy et al., 2021), satisfaction and pleasure (Harzer \& Ruch, 2013), positive affect such as joy, pride, or enthusiasm (Cable et al., 2015; LittmanOvadia et al., 2017), the cognitive component of life satisfaction (Dubreuil et al., 2016), satisfaction with environment for talents development (Oliinyk et al., 2021), cultural constituents of the social capital restoring (Kaasa, 2019) and well-being (Meyers \& Von Woerkom, 2017). Heintz and Ruch (2019) attempt to study which specific strengths (in Peterson and Seligman's 2004 framework) refer most strongly to job satisfaction. Their study shows that - similar to life satisfaction - zest, hope, curiosity, love, and gratitude - and emotional strengths in general - refer most strongly to overall job satisfaction. The relationship of the strengths to job satisfaction differs depending on occupation and age.

\section{Strengths in entrepreneurship research}

In this section we present the results of review of literature of character strengths of entrepreneurs. Due to the very limited number of studies in this field the method we applied was exhaustive literature review.

The empirical attempts to bridge the positive psychology and entrepreneurship domains by determining which character strengths are most strongly linked to entrepreneurship are very rare and raise more questions than they answer. In his study of 420 undergraduate and 250 MBA students, Hmieleski (2008) applies the Values in Action (VIA) scale to measure signature strengths, along with entrepreneurial intention and entrepreneurial alertness. Hmieleski concludes that the results failed to uncover a global relationship of specific character strengths with entrepreneurial intentions and alertness. However, some relationships were found with the sample split by sex. For men, there was a significant positive relationship between virtues of wisdom and knowledge (Hmieleski inappropriately names them "character strengths") with entrepreneurial intention and alertness. For women, the relationship between those variables was negative and highly significant. Among women the relationship between the virtue of justice and entrepreneurial intention and alertness was significant and positive, while among men the same relationship was negative and highly significant. Differences in gender percep- 
tion of values of work and entrepreneurial can be significant, hawever, sometimes they have not relevant evaluation by society due to the gender discrimination in economic relations (Bilan et al., 2020; Fernández Puente \& Sánchez-Sánchez, 2021).

The results of the study conducted on a sample of 200 entrepreneurs and expert advisors to entrepreneurs by Worrell (2009) indicate that entrepreneurs show a unique blend of character strengths. The top five character strengths for entrepreneurs in his sample are: authenticity, leadership, fairness, gratitude, and zest. Moreover, Worrell claims that the above is not just a list most common strengths but a set that spreads across various areas of the map proposed by Peterson (2006; see below). The framework proposed by Peterson spans between two dimensions: heart-mind; focus on self and focus on others. Heart strengths refer to emotional states, while mind strengths are more intellectual in nature. Focus on self and on others reflects either interpersonal or intrapersonal nature of a strength. The top five character strengths for entrepreneurs are evenly divided between the heart and the mind sides of this diagram. Interestingly, they are skewed towards a focus on others, as opposed to a focus on self. Surprisingly, some character strengths commonly associated with entrepreneurial action such as creativity - did not score high in Worrell's results. In fact, creativity was one of the bottom five entrepreneurs' character strengths. However, some note that Worrell used the VIA Brief Inventory of Strengths, which uses only one item to measure each strength.

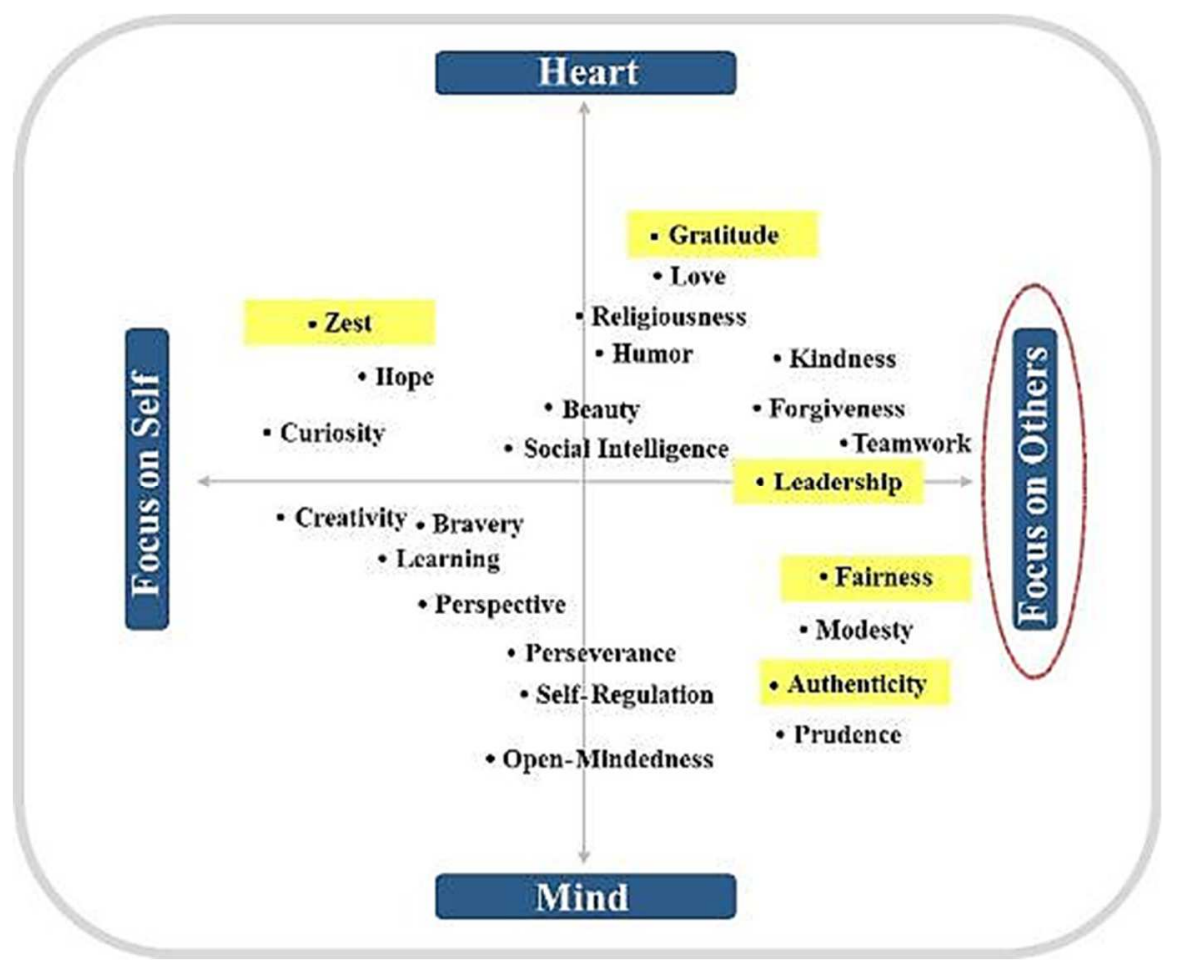

Figure 1. Character strengths of entrepreneur Source: Worrell (2009, p. 15).

Moreover, Worrell studies the consistency of interest and persistence of interest: grit. Grit captures perseverance and passion for long-term goals: working strenuously toward challenges, maintaining effort and interest over years despite failure, adversity, and plateaus in progress (Duckworth et al., 2007). In comparison to the general population, entrepreneurs score high on grit and exceptionally high on persistence of effort.

Both of the above articles shed some light on character strengths of entrepreneurs, but they are laden with serious limitations. First of all, in both cases the sample has a convenient character. Hmieleski (2008) studies students and Worrell (2009) samples 33 entrepreneurs and 174 expert advisors to entrepreneurs. The justification for the latter choice is that expert advisors may have more knowledge on character strengths of entrepreneurs, plus their opinion is not burdened by 
limitations of self-assessment. Moreover, all of the studied entrepreneurs were CEOs of successful companies and all of them were male. Secondly, Hmieleski focuses on relationships between virtues and entrepreneurship instead of relationships between individual character strengths and entrepreneurship. As virtues are aggregates of 3-5 character strengths, the application of that method limits interpretative opportunities. Finally, Hmieleski measures entrepreneurial intentions and alertness, instead of actual entrepreneurial action.

More recently, using the approach of person-entrepreneurship fit, Hmieleski and Sheppard (2019) studied the effect of strengths of creativity and teamwork on subjective well-being and performance of female and male entrepreneurs. The choice of those particular two strengths based on (positive) expectancy violation theory. Results show advantages of creativity (agentic strength) for women and teamwork (communal strength) for men in achieving high levels of subjective well-being and new venture performance. That effect is mediated by perceptions of person-work fit.

Some of the previous research concerns entrepreneurship-related behaviour at the workplace. Lee et al. (2016) suggest that developing strengths leads to finding more creative solutions to problems. Dubreuil et al. (2014) claim that this approach influences better adaptation to change. Moreover, results suggest that these relations are often mediated by positive emotions and engagement (Lavy \& Littman-Ovaida, 2017; Littman-Ovadia et al., 2017; Van Woerkom \& Meyers, 2015; Novak et al, 2021). The topic of strengths and talents of entrepreneurs has been also a matter of broader research unrelated to the particular framework of virtues, character, and signature strengths (Waters-Sobkowiak et al., 2018; Harris, 2019; Moayedfar \& Chafi, 2019; Pauli \& Pocztowski, 2019; Dissanayake, 2020).

Some authors use character strengths at collective level as predictors of cognitions and behaviours. For instance, Park and Peterson (2010) find that urban-level "head strengths" (intellectual and selffocused strengths such as curiosity and creativity) predict creativity and innovativeness, and generally that urban-level character strengths predict voting style. Similarly, on urban level, Ebert et al. (2019) study courage as an antecedent of business creation and survival. Park, Peterson, and Seligman (2006) and McGrath (2014) point to high consistency in character strengths across countries but also to the fact that some of the character strengths show some across-country variance and within-country consistence. Also Hofstede and McCrae (2004) confirm the appropriateness of using country-level personality-based measures as they find that mean personality scores from 33 countries are significantly and substantially correlated with culture dimension scores.

\section{Strengths at stages of venture development}

As entrepreneurial process is a multi-stage one (McMullen \& Shepherd, 2006), the important question is: Which strengths contribute to the success of the entrepreneur at various stages of the entrepreneurial process: opportunity identification, refinement of business concept and resource acquisition, survival and growth? Each of the stages is characterized by specific activities, so we may assume that entrepreneurs equipped with different strengths might be more or less effective at each of them. Even though some of the strengths are important at all stages of venture development, we try to attribute each strength to only one stage for clarity.

At the stage of opportunity recognition, the important strengths are primarily those grouped within the virtue of 'wisdom.' Baron and Ensley (2006) and Baron (2006) argue that the recognition of new business opportunities often involves pattern recognition: the cognitive process through which individuals identify meaningful patterns in complex arrays of events or trends. This process is facilitated by open-mindedness: the ability to look at the world from various perspectives. However, first of all, the starting point for opportunity recognition is entrepreneurial alertness which involves three elements: scanning and searching, association and connection, evaluation and judgment (Tang et al., 2012; Ganacarczyk \& Ujwary-Gil, 2021; Wach, Głodowska \& Maciejewski, 2022). We argue that the strength necessary for entrepreneurial alertness to exist is curiosity, and specifically interest in the outside world as it allows one to explore it for new opportunities. This is supported by some authors who introduce the concept of entrepreneurial curiosity (Jeraj \& Antoncic, 2013).

As Sarasvathy et al. (2003) point out, opportunity may have different forms and involves processes of recognition, discovery, and creation. We argue that for the last type of opportunity the strength of crea- 
tivity is especially important. It allows one to propose novel and useful solutions, products, and services. For the opportunity to be recognized and used, the necessary strength is hope, which allows one to create a positive image of the future and perception of the feasibility of a task. Therefore, we argue that:

Proposition 1: Curiosity, creativity, open-mindedness, and hope are the strengths that contribute to successful opportunity recognition.

Hope is the strength that might allow entrepreneurs to transit from the stage of opportunity recognition to refinement of business concept and resource acquisition. Especially the component of hope - namely a willingness to find multiple ways to exploit the opportunity - takes part in the transition. Moreover, hope allows for the internalization of the capacity of using an opportunity. Furthermore, opportunity exploitation involves the willingness to take risks, which corresponds to the strength of bravery as there is strong evidence that entrepreneurs tend to underestimate risk compared to managers (Palich \& Bagby, 1995; Dankiewicz et al., 2020).

From the perspective of person-entrepreneurship fit, it is important that the activity that a business owner undertakes is aligned with personality. This is where the strength of integrity comes into play. An entrepreneur must be aware of own personal characteristics and must assure that they are reflected in the venture. The process of the refinement of business concept is obviously dynamic and involves rapid learning by the business owner. Therefore, the strength of the love of learning is critical for its success as it allows one to absorb the necessary knowledge and skills and iterate the business concept so as to grasp it masterfully.

For the process of resource acquisition, the strengths that are especially relevant are those related to building social capital: social intelligence and kindness. They allow one to build social relations that might be then used to acquire resources necessary for the exploitation of an opportunity (Nieto \& González-Álvarez, 2016). Social intelligence allows one to adjust to social situations and various stakeholders. Kindness facilitates building relationships based on reciprocity. Therefore, we argue that:

Proposition 2: Bravery, integrity, the love of learning, social intelligence, and kindness are the strengths that contribute to the successful refinement of business concept and resource acquisition.

At the stage of survival and growth, the strengths that are the most relevant for success are persistence, self-regulation, humour, zest, and the strengths grouped under the virtue of humanity: teamwork, fairness, and leadership. Persistence allows one to keep going when with a goal in mind even in the face of obstacles. It also helps one to finish what one started. Self-regulation refers to persistence and helps us to manage our vices and habits. It is also useful in negotiations as it allows us to stay calm under pressure an manage impulses and emotions. Zest is useful for staying enthusiastic towards a business activity and being energetic and activated. Zesty entrepreneurs use their energy to the fullest degree.

Managing a business is also a social process, so humanity-related strengths are critical for the success. Leadership and fairness are necessary to manage employees, while teamwork is particularly useful in business partnerships. Finally, as entrepreneurs themselves claim, humour is quite important in daily business practice (Lin, Li, \& Han, 2018). It allows one to cope with stress and sometimes is the last resort in the face of adversity. Taking the above into consideration, we propose that:

Proposition 3: Persistence, self-regulation, zest, humour, leadership, teamwork, and fairness are the strengths that contribute to the survival and growth of entrepreneurial ventures.

As Baron and Ensley (2006) empirically prove, the experience that entrepreneurs gain allows them for better recognition of opportunities. We argue that the strength facilitating that process is perspective or, more specifically, the ability to use experience to link seemingly unrelated events. This way, through perspective and experience, entrepreneurs can close the cycle and build an upward spiral of increasingly effective opportunity recognition, refinement of business concept and resource acquisition, along with survival and growth. Therefore, we argue that perspective is the strength that allows entrepreneurs to accumulate the entrepreneurial experience and to become successful serial or portfolio entrepreneurs:

Proposition 4: Perspective contributes to the successful opening of multiple cycles of entrepreneurial processes. 


\section{CONCLUSIONS}

In this article we attempted to conceptually extend the understanding of the effect of personality traits on success in running a business at various stages of venture development. We sought to attribute the character strengths that are most helpful in opportunity recognition, the creation of business model and resource acquisition, along with daily business practice. In effect, our study produced a framework of character strengths and stages of venture development. However, we must address here why the framework does not consider some character strengths present in the literature. First of all, entrepreneurs are characterized by low level of most of the strengths grouped under the virtue of temperance: forgiveness, modesty, and prudence. There is evidence that very often business owners are overconfident (Koellinger et al., 2007). Second, there is strong evidence that they are not prudent and underestimate risks (Palich \& Bagby, 1995). Other strengths that are absent from the framework are those grouped within the virtue of transcendence: gratitude, appreciation of beauty, excellence, and spirituality. These strengths do not strongly link to any of the stages of venture development, although there is some evidence that spirituality might be generally important to running a business (Ganzin, Islam, \& Suddaby, 2019).

Notably, the diversity of entrepreneurs, opportunities, and actions demands further consideration. For instance, various personalities might derive more or less benefit from various forms of business planning. Therefore, a question arises regarding the role of planning in utilizing signature strengths. Do entrepreneurs with various signature strengths derive different benefits (or suffer from disadvantages) of various forms of business planning? This would require us to ask about business planning and its forms. In this regard, Frese et al. (2000) differentiate "complete planning," "critical point planning," "opportunistic strategy," and "reactive approach." Moreover, in the research of the predictive role of personality on entrepreneurial behaviour, we must consider the situational parameters which are known to increase the predictive power of traits (Magnusson \& Endler, 1977). This could include the need for relationships with customers that e.g. could require a high degree of kindness. Such a situational approach is necessary to consider the relevance of character strengths.

Moreover, Rauch and Frese (2007) suggest that the effects of personality on success (or performance) might not be linear. This might also concern character strengths. The abundance of such strengths as kindness or even creativity might damage the performance of entrepreneurial venture due to the lack of assertiveness (high kindness) or creation of products/services that are so novel that they become unusable (high creativity). Thus, the 'too much of a good thing' rule might also apply to entrepreneurs' strengths.

Regarding policy implications, some studies indicate that the important impact of strengths use on work outcomes is created by organizational support for strengths use through a greater reliance on personal strengths (Stander et al., 2014; Van Woerkom et al., 2016). Translating it to entrepreneurial work, the question arises regarding country-level support for the use of particular strengths related to running a business. This area should be considered by policymakers who create programs that support entrepreneurship at the country level.

At the individual level the investigation provides practical implications and recommendations for entrepreneurial job crafting. What is critical in this respect is entrepreneurs' self-awareness about their talents. The next step is adjusting to various stages, circumstances, and social settings (having a business partner, help from relatives, funding by business angels or venture capital). Then, the situation of business partnership requires the identification of strengths of each partner and a conscious process of sharing business activities among them based on their talents structure. A strength-based approach may also be used in investment decisions, while in more institutional setting - by business angels and venture capitalists. They might want to assess investees' talents and their fit with the funded venture, but they might also be interested in investment in strengths of an entrepreneur bundled with investment in a business. Finally, important practical implications could be formulated for education in entrepreneurship on various stages. It is as important to enhance the self-awareness of future entrepreneurs as teaching them specific skills in running a business. Therefore, the education of entrepreneurship should be at least partly focused on self-reflection on talents and personality, including character strengths. 
The article has some limitations. As it does not include any empirical investigation, the propositions are of purely theoretical nature. Moreover, the lack of the literature entrepreneurs' strengths disallows a more precise identification of the relevance of certain strengths' possession and use at particular stages of venture development. Finally, the propositions formulated above share the limitations of the framework of strengths that was designed to capture general public strengths and not those of entrepreneurs.

To sum up, we argue that using the above framework of character strengths in entrepreneurship research can progress the debate on entrepreneurs' traits and their use in business. Moreover, the framework's application opens future research opportunities by the possible application of new research methods. For instance, a large share of research on character strengths is intervention-based. Interventions regarding entrepreneurs are more difficult than those regarding employees or managers, but results might be more than interesting. Another venue for the future research might lie in relating the strengths to more well-grounded aspects of personality that could disclose the stability of entrepreneurs' signature strengths. Finally, instead of just analysing the possession of certain strengths, the investigation of strengths use in day-to-day setting might uncover some short-term consequences of the application of particular signature strengths by specific types of entrepreneurs in tasks they perform.

\section{REFERENCES}

Aldrich H.E. (1999). Organizations Evolving. London: Sage.

Bakker, A.B., Hetland, J., Olsen, O.K., \& Espevik, R. (2019). Daily strengths use and employee well-being: The moderating role of personality. Journal of Occupational and Organizational Psychology, 92, 144-168. https://doi.org/10.1111/joop.12243

Baron, M.A. (2006). Opportunity recognition as pattern recognition: How entrepreneurs "connect the dots" to identify new business opportunities. Academy of Management Perspectives, 20, 104-119. https://doi.org/10.5465/amp.2006.19873412

Baron, M.A., \& Ensley, M.D. (2006). Opportunity recognition as the detection of meaningful patterns: Evidence from comparisons of novice and experienced entrepreneurs. Management Science, 52, 1331-1344. https://doi.org/10.1287/mnsc.1060.0538

Bilan, Y., Mishchuk, H., Samoliuk, N., \& Mishchuk, V. (2020). Gender discrimination and its links with compensations and benefits practices in enterprises. Entrepreneurial Business and Economics Review, 8(3), 189-204. https://doi.org/10.15678/EBER.2020.080311

Biswas-Diener, R. (2006). From the equator to the north pole: A study of character strengths. Journal of Happiness Studies: An Interdisciplinary Forum on Subjective Well-Being, 7(3), 293-310. https://doi.org/10.1007/s10902-005-3646-8

Buckingham, M., \& Clifton, D.O. (2001). Now, discover your strengths. New York, NY: Free Press.

Cable, D., Lee, J.J., Gino, F., \& Staats, B.R. (2015). How Best-self Activation Influences Emotions, Physiology and Employment Relationships. (Harvard Business School NOM Unit Working Paper, 16-29).

Castellanos1, J. D., \& George2, B. (2020). Boardroom leadership: The board of directors as a source of strategic leadership. Economics and Business Review, 20(1), 103-119 DOI: 10.18559/ebr.2020.1.5

Dissanayake, K. (2020). Perception of strengths from the voice of women micro entrepreneurs: A study in Sri Lanka. Studies in Indian Place Names, 40(6), 27-38.

Coppola, A., lanuario, S., Chinnici, G., Di Vita, G., Pappalardo, G., \& D’Amico, D. (2018). Endogenous and Exogenous Determinants of Agricultural Productivity: What Is the Most Relevant for the Competitiveness of the Italian Agricultural Systems?. AGRIS on-line Papers in Economics and Informatics, 10(2), 33-47. https://doi.org/10.7160/aol.2018.100204.

Dankiewicz, R., Ostrowska-Dankiewicz, A., \& Bulut, C. (2020). The attitudes of entrepreneurs of the small and medium-sized enterprises sector in Poland to key business risks. Equilibrium. Quarterly Journal of Economics and Economic Policy, 15(3), 511-536. https://doi.org/10.24136/eq.2020.023.

Dubreuil, P., Forest, J., \& Courcy, F. (2014). From strengths use to work performance: The role of harmonious passion, subjective vitality, and concentration. The Journal of Positive Psychology, 9(4), 335-349.

Dubreuil, P., Forest, J., Gillet, N., Fernet, C., Thibault-Landry, A., Crevier-Braud, L., \& Girouard, S. (2016). Facilitating well-being and performance through the development of strengths at work: Results from an intervention 
program. International Journal of Applied Positive Psychology, 1(1), 1-19. https://doi.org/10.1080/17439760.2014.898318

Duckworth, A., Peterson, C., Matthews, M., \& Kelly, D. (2007). Grit: Perseverance and passion for long-term goals. Journal of Personality and Social Psychology, 92(6), 1087-1101. https://doi.org/10.1037/00223514.92.6.1087

Ebert, T., Götz, F.M., Obschonka, M., Zmigrod, L., \& Rentfrow, P.J. (2019). Regional variation in courage and entrepreneurship: The contrasting role of courage for the emergence and survival of start-ups in the United States. Journal of Personality, 87(5), 1039-1055. https://doi.org/10.1111/jopy.12454

Fernández Puente, A. C., \& Sánchez-Sánchez, N. (2021). Understanding executive women's perspectives on job satisfaction and their different domains. Economics and Sociology, 14(1), 159-177. doi:10.14254/2071789X.2021/14-1/11

Forest, J., Mageau, G.A., Crevier-Braud, L., Bergeron, É., Dubreuil, P., \& Lavigne, G.L. (2012). Harmonious passion as an explanation of the relation between signature strengths' use and well-being at work: Test of an intervention program. Human Relations, 65(9), 1233-1252. https://doi.org/10.1177/0018726711433134

Fredrickson, B.L. (2001). The role of positive emotions in positive psychology: The broaden-and-build theory of positive emotions. American Psychologist, 56(3), 218. https://doi.org/10.1037/0003-066X.56.3.218

Frese, M., \& Gielnik, M.M. (2014). The psychology of entrepreneurship. Annual Review of Organizational Psychology and Organizational Behavior, 1(1), 413-438. https://doi.org/10.1146/annurev-orgpsych-031413-091326

Frese, M., Van Gelderen, M., \& Ombach, M. (2000). How to plan as a small scale business owner: psychological process characteristics of action strategies and success. Journal of Small Business Management, 38(2), 1-18.

Ganacarczyk, M., \& Ujwary-Gil, A. (2021). Entrepreneurial cognition or judgment: Management and economics approaches to the entrepreneur's choices. Journal of Entrepreneurship, Management and Innovation, 17(1), 7-23. https://doi.org/10.7341/20211710

Ganzin, M., Islam, G., \& Suddaby, R. (2020). Spirituality and entrepreneurship: The role of magical thinking in $\begin{array}{llll}\text { future-oriented } \quad \text { sensemaking. } & \text { Organization }\end{array}$ https://doi.org/10.1177/0170840618819035

Gartner, W.B. (1988). "Who is an entrepreneur?" is the wrong question. American Journal of Small Business, 12(4), 11-32. https://doi.org/10.1177/104225878801200401

Ghielen, S.T.S., van Woerkom, M., \& Christina Meyers, M. (2017). Promoting positive outcomes through strengths interventions: A literature review. Journal of Positive Psychology, 13(6), 573-585. https://doi.org/10.1080/17439760.2017.1365164

Harris T. (2019). Start-up A Practical Guide to Starting and Running a New Business. Cham: Springer.

Harzer, C., \& Ruch, W. (2013). The application of signature character strengths and positive experiences at work. Journal of Happiness Studies, 14(3), 965-983. https://doi.org/10.1007/s10902-012-9364-0

Heintz, S., \& Ruch, W. (2020). Character strengths and job satisfaction: differential relationships across occupational groups and adulthood. Applied Research in Quality of Life, 15(2), 503-527. https://doi.org/10.1007/s11482-018-9691-3

Heslin P.A., Latham G.P., \& Vandewalle D. (2005). The effect of implicit person theory on performance appraisals. Journal of Applied Psychology, 90(5), 842-856. https://doi.org/10.1037/0021-9010.90.5.842

Hmieleski, K. (2008). Sex differences in entrepreneur signature strengths (summary). Frontiers of Entrepreneurship Research, 28(4), 1.

Hmieleski, K.M., \& Sheppard, L.D. (2019). The Yin and Yang of entrepreneurship: Gender differences in the importance of communal and agentic characteristics for entrepreneurs' subjective well-being and performance. Journal of Business Venturing, 34(4), 709-730. https://doi.org/10.1016/j.jbusvent.2018.06.006

Hofstede, G., \& McCrae, R.R. (2004). Personality and culture revisited: Linking traits and dimensions of culture. Cross-Cultural Research, 38(1), 52-88. https://doi.org/10.1177/1069397103259443

Jeraj, M., \& Antoncic, B. (2013). A conceptualization of entrepreneurial curiosity and construct development: A multi-country empirical validation. Creativity Research Journal, 25(4), 426-435. https://doi.org/10.1080/10400419.2013.843350

Kaasa, A. (2019). Determinants of individual-level social capital: Culture and personal values. Journal of International Studies, 12(1), 9-32. doi:10.14254/2071- 8330.2019/12-1/1 
Koellinger, P., Minniti, M., \& Schade, C. (2007). "I think I can, I think I can": Overconfidence and entrepreneurial behavior. Journal of Economic Psychology, 28(4), 502-527. https://doi.org/10.1016/j.joep.2006.11.002

Lavy, S., \& Littman-Ovadia, H. (2017). My better self using strengths at work and work productivity, organizational citizenship behavior, and satisfaction. Journal of Career Development, 44(2), 95-109.

Lee, J.J., Gino, F., Cable, D., \& Staats, B.R. (2016). Preparing the self for team entry: How relational affirmation improves team performance. Harvard Business School NOM Unit Working Paper, (16-111).

Levie, J., \& Autio, E. (2011). Regulatory burden, rule of law, and entry of strategic entrepreneurs: An international panel study. Journal of Management Studies, 48(6), 1392-1419. https://doi.org/10.1111/j.14676486.2010.01006.x

Lin, S., Li, J., \& Han, R. (2018). Coping humor of entrepreneurs: Interaction between social culture and entrepreneurial experience. Frontiers in Psychology, 9, article 1449. https://doi.org/10.3389/fpsyg.2018.01449

Linley, P.A. (2008). Average to At. Coventry: CAPP Press.

Littman-Ovadia, H., \& Steger, M. (2010). Character strengths and well-being among volunteers and employees: Toward an integrative model. Journal of Positive Psychology, 5(6), 419-430. https://doi.org/10.1080/17439760.2010.516765

Littman-Ovadia, H., Lavy, S., \& Boiman-Meshita, M. (2017). When theory and research collide: Examining correlates of signature strengths use at work. Journal of Happiness Studies, 18(2), 527-548. https://doi.org/10.1007/s10902-016-9739-8

Magnusson, D., \& Endler, N.S. (1977). Interactional psychology: Present status and future prospects. In D. Magnusson \& N.S. Endler (Eds.), Personality at the crossroads: Current issues in interactional psychology, (pp. 336). Hillsdale, NJ: Lawrence Erlbaum Associates.

Meyer, N., \& Krüger, N. (2021). South African female entrepreneurs' motivational factors: Differences between young and established businesses owners. Forum Scientiae Oeconomia, 9(1), 75-90. https://doi.org/10.23762/FSO_VOL9_NO1_5

McGrath, R.E. (2014). Character strengths in 75 nations: An update. Journal of Positive Psychology, 10(1), 41-52. https://doi.org/10.1080/17439760.2014.888580

McMullen, J.S., \& Shepherd, D.A. (2006). Entrepreneurial action and the role of uncertainty in the theory of the entrepreneur. Academy of Management Review, 31(1), 132-152. https://doi.org/10.5465/amr.2006.19379628

Meyers, M.C., \& Van Woerkom, M. (2017). Effects of a strengths intervention on general and work-related wellbeing: The mediating role of positive affect. Journal of Happiness Studies, 18(3), 671-689. https://doi.org/10.1007/s10902-016-9745-x

Miglianico, M., Dubreuil, P., Miquelon, P., Bakker, A.B., \& Martin-Krumm, C. (2020). Strength use in the workplace: A literature review. Journal of Happiness Studies, 21(2), 737-764. https://doi.org/10.1007/s10902019-00095-w

Mischel, W., \& Shoda, Y. (1998). Reconciling processing dynamics and personality dispositions. Annual Review of Psychology, 49(1), 229-258. https://doi.org/10.1146/annurev.psych.49.1.229

Moayedfar, R., \& Madani Chafi, M. (2019). A Theoretical Expansion of Talent Allocation Model: Evidence from Selected Developing Countries from 2014-2018. Entrepreneurial Business and Economics Review, 7(4), 5772. https://doi.org/10.15678/EBER.2019.070404

Novák, J., Benda, P., Šilerová, E., Vaněk, J., \& Kánská, E. (2021). Sentiment Analysis in Agriculture. AGRIS on-line Papers in Economics and Informatics, 13(1), 121-130. https://doi.org/10.7160/aol.2021.130109.

Nieto, M., \& González-Álvarez, N. (2016). Social capital effects on the discovery and exploitation of entrepreneurial opportunities. International Entrepreneurship and Management Journal, 12(2), 507-530. https://doi.org/10.1007/s11365-014-0353-0

Nijs, S., Gallardo-Gallardo, E., Dries, N., \& Sels, L. (2014). A multidisciplinary review into the definition, operationalization, and measurement of talent. Journal of World Business, 49(2), 180-191. https://doi.org/10.1016/j.jwb.2013.11.002

Novák, J., Benda, P., Šilerová, E., Vaněk, J., \& Kánská, E. (2021). Sentiment Analysis in Agriculture. AGRIS on-line Papers in Economics and Informatics, 13(1), 121-130. https://doi.org/10.7160/aol.2021.130109.

Oliinyk, O., Bilan, Y., Mishchuk, H., Akimov, O. \& Vasa, L. (2021). The Impact of Migration of Highly Skilled Workers on The Country's Competitiveness and Economic Growth. Montenegrin Journal of Economics, 17(3), 7-19. 
Palich, L.E., \& Bagby, D.R. (1995). Using cognitive theory to explain entrepreneurial risk-taking: Challenging conventional wisdom. Journal of Business Venturing, 10(6), 425-438. https://doi.org/10.1016/08839026(95)00082-J

Pauli, U., \& Pocztowski, A. (2019). Talent Management in SMEs: An Exploratory Study of Polish Companies. Entrepreneurial Business and Economics Review, 7(4), 199-218. https://doi.org/10.15678/EBER.2019.070412

Park, N., \& Peterson, C. (2010). Does it matter where we live? The urban psychology of character strengths. American Psychologist, 65(6), 535-547. https://doi.org/10.1037/a0019621

Park, N., Peterson, C., \& Seligman, M.E. (2006). Character strengths in fifty-four nations and the fifty US states. Journal of Positive Psychology, 1(3), 118-129. https://doi.org/10.1080/17439760600619567

Peterson, C. (2006). A primer in positive psychology. Oxford, UK: Oxford University Press.

Peterson, C., \& Seligman, M.E.P. (2004). Character strengths and virtues: A handbook and classification. New York: Oxford University Press.

Pfeffer J., \& Sutton R.I. (2006). Hard Facts, Dangerous Half-Truths, and Total Nonsense: Profiting from EvidenceBased Management. Boston: Harvard Business School Press.

Quinlan, D., Swain, N., \& Vella-Brodrick, D.A. (2012). Character strengths interventions: Building on what we know for improved outcomes. Journal of Happiness Studies, 13(6), 1145-1163. https://doi.org/10.1007/s10902-011-9311-5

Rauch, A., \& Frese, M. (2000). Psychological approaches to entrepreneurial success: A general model and an overview of findings. International Review of Industrial and Organizational Psychology, 15, 101-142.

Rauch, A., \& Frese, M. (2007). Born to be an entrepreneur? Revisiting the personality approach to entrepreneurship. In J.R. Baum, M. Frese, \& R.A. Baron (Eds.), The organizational frontiers. The psychology of entrepreneurship, (pp. 41-65). Mahwah, NJ, US: Lawrence Erlbaum Associates Publishers.

Rodríguez-Castro, D.Y., \& Aparicio, J. (2021). Introducing a functional framework for integrating the empirical evidence about higher education institutions' functions and capabilities: A literature review. Journal of Entrepreneurship, Management and Innovation, 17(1), 231-267. https://doi.org/10.7341/20211718

Ryan, R.M., \& Deci, E.L. (2001). On happiness and human potentials: A review of research on hedonic and eudaimonic well-being. Annual Review of Psychology, 52(1), 141-166. https://doi.org/10.1146/annurev.psych.52.1.141

Sarasvathy S.D., Dew, N., Velamuri, S.R., \& Venkataraman, S. (2003). Three views of entrepreneurial opportunity. In Z.J. Acs, \& D.B. Audretsch (Eds.), Handbook of entrepreneurship research. An interdisciplinary survey and introduction (pp. 141-160). Boston: Kluver Academic Publishers.

Seligman, M.E.P., \& Csikszentmihalyi, M. (2000). Positive psychology: An introduction. American Psychologist, 55, 5-14. https://doi.org/10.1037/0003-066X.55.1.5

Shane S., \& Venkataraman, S. (2000). The promise of entrepreneurship as a field of research. Academy of Management Review, 25(1), 17-26. https://doi.org/10.5465/amr.2000.2791611

Solesvik, M.Z. (2019). Entrepreneurial competencies and intentions: The role of higher education. Forum Scientiae Oeconomia, 7(1), 9-23. https://doi.org/10.23762/FSO_VOL7_NO1_1

Stander, F.W., Mostert, K., \& de Beer, L.T. (2014). Organisational and individual strengths use as predictors of engagement and productivity. Journal of Psychology in Africa, 24(5), 403-409. https://doi.org/10.1080/14330237.2014.997007

Tang, J., Kacmar, K.M.M., \& Busenitz, L. (2012). Entrepreneurial alertness in the pursuit of new opportunities. Journal of Business Venturing, 27(1), 77-94. https://doi.org/10.1016/j.jbusvent.2010.07.001

Tshikovhi, N., Dziike, F., \& Moyo, S. (2021). Restarting for the thrill: Behavioural addiction to entrepreneurship. International Entrepreneurship Review, 7(3), 37-46. https://doi.org/10.15678/IER.2021.0703.03

Van Woerkom, M., Bakker, A.B., \& Nishii, L.H. (2016). Accumulative job demands and support for strength use: Fine-tuning the JD-R model using COR theory. Journal of Applied Psychology, 101(1), 141-150. https://doi.org/10.5465/ambpp.2015.321

Wach, K., \& Głodowska, A (2021). How do demographics and basic traits of an entrepreneur impact the internationalization of firms?. Oeconomia Copernicana, 12(2), 399-424. https://doi.org/10.24136/oc.2021.014

Wach, K., Głodowska, A., \& Maciejewski, M. (2022 - In Press). Entrepreneurial orientation and opportunities recognition on foreign markets: Empirical evidence from Central Europe. European Journal of International Management - Ahead-of-Print (available online). 


\section{Author}

\section{Przemysław Zbierowski}

Associate Professor at the University of Economics in Katowice, Head of the Department of Human Resource Management. His research interests include positive psychology and its implication in management, entrepreneurship with a special focus on the psychology of entrepreneurship, along with the mental health and wellbeing of entrepreneurs, but also leadership, especially the use of a positive approach in investigating the outcomes of leaders' style and behaviours.

Correspondence to: Prof. UE, dr hab. Przemysław Zbierowski, Department of Human Resource Management, University of Economics in Katowice, 1 Maja 50, 40-287 Katowice, Poland, email: przemyslaw.zbierowski@ue.katowice.pl

ORCID (1) http://orcid.org/0000-0001-6144-1940

\section{Milena Gojny-Zbierowska}

Assistant Professor at the University of Economics in Katowice, at the Department of Entrepreneurship. Her research interests include psychology of business and entrepreneurship with the special focus on positive leadership, perceived organizational support, psychological capital and psychological safety.

Correspondence to: Dr Milena Gojny-Zbierowska, Department of Entrepreneurship, University of Economics in Katowice, 1 Maja 50, 40-287 Katowice, Poland, email: milena.gojny@ue.katowice.pl ORCID (1) http://orcid.org/0000-0002-5385-9324

\section{Acknowledgements and Financial Disclosure}

The research was carried out within the research project 2017/27/B/HS4/02172 funded by the National Science Centre, Poland.

\section{Conflict of Interest}

The author declares that the research was conducted in the absence of any commercial or financial relationships that could be construed as a potential conflict of interest.

\section{Copyright and License}

This article is published under the terms of the Creative Commons

Attribution - NoDerivs (CC BY-ND 4.0) License

http://creativecommons.org/licenses/by-nd/4.0/ 
